\title{
Prevalence of Cam and Pincer Deformities in the X-Rays of Asymptomatic Individuals
}

\author{
Steffen Thier, ${ }^{1}$ Daniel Gerisch, ${ }^{1}$ Christel Weiss, ${ }^{2}$ Stefan Fickert, ${ }^{1,3}$ and Alexander Brunner ${ }^{4}$ \\ ${ }^{1}$ Orthopedic and Trauma Surgery Center, University Medical Centre Mannheim, University of Heidelberg, \\ Theodor-Kutzer-Ufer 1-3, 68167 Mannheim, Germany \\ ${ }^{2}$ Institute of Biostatistics, Medical Faculty Mannheim, University of Heidelberg, Ludolf-Krehl-Straße 13-17, 68167 Mannheim, Germany \\ ${ }^{3}$ Sporthopaedicum Straubing, Bahnhofplatz 27, 94315 Straubing, Germany \\ ${ }^{4}$ Department of Orthopaedic Surgery, Medical University Innsbruck, Anichstrasse 35, 6020 Innsbruck, Austria
}

Correspondence should be addressed to Alexander Brunner; a-r.brunner@web.de

Received 23 June 2017; Accepted 28 November 2017; Published 18 December 2017

Academic Editor: Sae Hoon Kim

Copyright (C) 2017 Steffen Thier et al. This is an open access article distributed under the Creative Commons Attribution License, which permits unrestricted use, distribution, and reproduction in any medium, provided the original work is properly cited.

Objective. The presence of radiological signs of femoroacetabular impingement (FAI) is not necessarily associated with symptoms. Hence, the prevalence of cam and pincer deformities in the overall population may be underestimated. The purpose of this study was to screen an unselected cohort of people without hip symptoms for native radiological signs of cam and pincer deformities to determine their actual prevalence. Materials and Methods. 110 asymptomatic patients had AP pelvis X-rays and cross-table hip $\mathrm{X}$-rays performed. We evaluated the images for the presence of cross-over signs and measured lateral center edge (LCE) angles, alpha angles ( $\alpha$-angles), and femoral offset ratios. Results. Positive cross-over signs were seen in $34 \%$; LCE angles $>40^{\circ}$ in $13 \%$; and femoral offset ratios $<0.18$ in $43 \%$. In $41 \%$ of the patients, $\alpha$-angles were $>50^{\circ}$. Male patients showed significantly higher $\alpha$ angles, lower offset ratios, and a higher prevalence of cross-over signs. In contrast, female patients had significantly higher LCE angles. Conclusion. According to our data, radiological signs of cam and pincer deformities are common in asymptomatic people. In clinical practice, patients presenting with hip pain and radiological signs of FAI should undergo further diagnostic evaluation. However, in asymptomatic patients, no further evaluation is recommended.

\section{Introduction}

During the last decade, femoroacetabular impingement (FAI) has been commonly recognized as a cause of chronic hip pain and a possible predisposing condition for the development of early osteoarthritis [1-5]. During internal rotation and flexion of the hip, repetitive abutment between the femoral neck junction and the acetabular rim may lead to a cascade of degenerative changes including labrum disruption, chondromalacia, and peripheral acetabular cartilage delamination $[1,6,7]$. In general, FAI may be caused by two major types of anatomic abnormalities. Cam-type FAI is characterized by an aspherical configuration of the femoral head-neck junction, and pincer-type FAI is associated with acetabular overcoverage or retroversion. Interestingly, several studies have shown that most patients actually have a combined form (mixed FAI) of the two types [4, 6-11].
However, the presence of these anatomic abnormalities is not necessarily associated with clinical symptoms. In daily life, a considerable percentage of people with cam or pincer deformities may not feel any pain, and their anatomic pathology may remain undetected. Recently, a number of studies have been performed to evaluate the prevalence of cam or pincer deformities in asymptomatic people. Hack et al. reported a prevalence of $14 \%$ after screening 200 volunteers from their hospital staff using MRI [12]. Likewise, Reichenbach et al. evaluated a cohort of asymptomatic recruits with MRI and found a prevalence of $24 \%$ [13]. In regular participants of high impact sports (such as football, ice hockey, or skiing), even higher percentages-between 55\% and 87\%-have been reported [14-16].

Most of the studies that have screened populations for cam or pincer deformities used MRI or CT scans. However, in daily clinical practice, patients who present with hip 


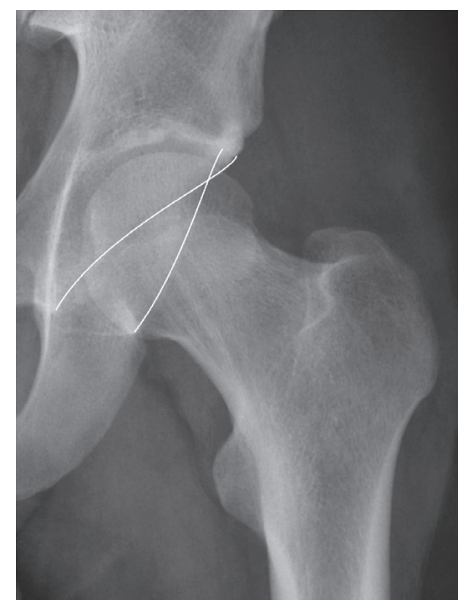

(a) X-rays were evaluated for the presence of the cross-over signs

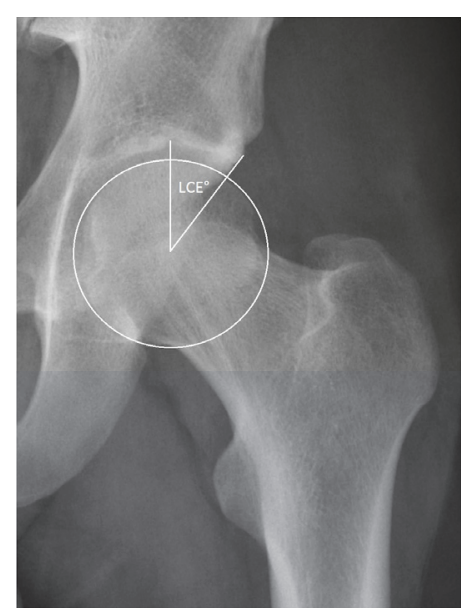

(b) Measurement of the lateral centeredge (LCE) angles as proposed by Wiberg [20]

Figure 1

pain will first have native $\mathrm{X}$-rays obtained $[4,6,17,18]$. To improve the interpretation accuracy of these $\mathrm{X}$-rays, it may be helpful to know the prevalence of deformities associated with FAI on plain films in the average asymptomatic population. Until recently, studies evaluating X-rays of asymptomatic people for cam and pincer deformities were limited. Therefore, the purpose of this study was to screen an unselected cohort of people without hip symptoms for native radiological signs associated with cam and/or pincer FAI. We hypothesized that a significant percentage of asymptomatic people would have radiological signs of FAI on native $\mathrm{X}$-rays.

\section{Material and Methods}

This retrospective study was approved by the Ethics Committee of the Medical University Heidelberg (Process number 2011-370N-MA) and is in accordance with the declaration of Helsinki. Between 2010 and 2011, AP pelvis and crosstable radiographs were routinely performed for patients who presented to our emergency department with acute trauma to the hip or femur. The X-rays and medical files of these patients were retrospectively evaluated.

Inclusion criteria for the study included the presence of AP pelvis and cross-table radiographs of adequate quality, information on the patient's medical history, and patient age greater than 18 years.

Patients who reported having hip symptoms (e.g., pain or limited range of motion) before the presenting trauma and those who sustained femoral or acetabular fractures during the presenting trauma were excluded. Further exclusion criteria included prior hip surgery, a history of hip fracture, congenital hip pathologies (dysplasia, Legg-Calve-Perthes disease, and slipped capital femoral epiphysis), grade IV osteoarthritis on X-ray according to the Kellgren-Lawrence scale [19], and neurological pathologies that could affect physiological loading of the hip.
Finally, 110 patients ( 60 women, 50 men) with 114 hips (60 left, 54 right) and a mean age of 56 years (range: $18-100$ years, SD: 22.4 years) were included in this study.

2.1. X-Rays. Standard AP pelvic radiographs were performed with the patients in supine position and the hip extended and internally rotated $15^{\circ}$. The film-focus distance was 1.2 meters, with the central beam directed toward the intersection of the line connecting both anterior-superior iliac spines and a vertical line through the symphysis $[2,22]$.

$\mathrm{X}$-ray quality was considered adequate when both obturator foramen and iliac crests were symmetrically projected, and the coccyx was projected $1-2 \mathrm{~cm}$ caudal to the symphysis [2].

Cross-table lateral radiographs were performed with the patient in the supine position and the hip extended and internally rotated $15^{\circ}$. The contralateral hips and knees were flexed beyond $80^{\circ}$. The central X-ray beam was positioned parallel to the ground with an inclination of $65^{\circ}$, according to the axis of the femur, and directed toward the inguinal fold $[7,23]$.

2.2. Radiological Evaluation. Radiographs were assessed on a SYNGO-Viewer workstation (Siemens Healthcare, Erlangen, Germany). A third person not involved further in the evaluations removed patient data from the X-rays. To assess the prevalence of pincer deformities, two orthopaedic surgery consultants independently evaluated the AP pelvis X-rays in random order for the presence of the cross-over signs (Figure 1(a)) $[8,11,24]$ and measured the lateral center-edge (LCE) angles as proposed by Wiberg (Figure 1(b)) [20]. A LCE angle of $40^{\circ}$ or higher was considered to represent a pincer deformity. To assess the prevalence of cam deformities, cross-table lateral radiographs were evaluated for femoral asphericity by the measurement of $\alpha$-angles (Figure 2(a)), as described by Nötzli et al. [21], and by the ratio between the anterior offset and the diameter of the femoral head (i.e., the 


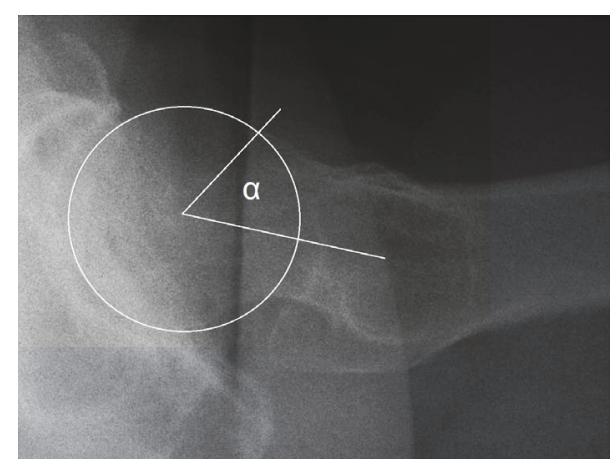

(a) Measurement of $\alpha$-angles, as described by Nötzli et al. [21]

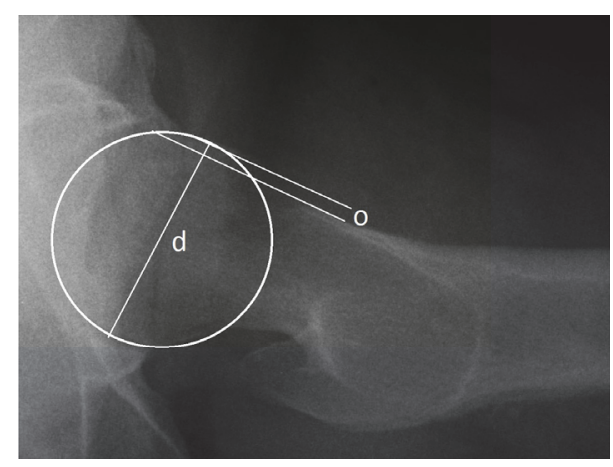

(b) The offset ratio was measured as the ratio between the anterior offset and the diameter of the femoral head [22]

FIGURE 2

offset ratio; Figure 2(b)). An offset ratio $<0.18$ was considered pathological [22]. Finally, all radiographs were assessed for grade of osteoarthritis according to the Kellgren-Lawrence grading scale [19].

Mean values of the measured parameters (LCE angles, $\alpha$-angles, and offset ratios) were used for further analyses. In cases with inconsistencies regarding the presence of a cross-over signs or the grade of osteoarthritis, X-rays were reevaluated by both orthopaedic surgeons together and a consensus decision was made.

2.3. Statistical Analysis. A Shapiro-Wilk analysis was performed to test linear data for normal distribution. We calculated mean values for linear data. The number of patients with positive cross-over signs, LCE angles $\geq 40^{\circ}$, and offset ratios $<0.18$ were calculated. Student's $t$-test was used to compare mean values for linear data, and the chi-square test was used to compare frequencies for nominal data. Since the $\alpha$-angle cut-off considered pathological varies in the literature, we calculated the number of patients with $\alpha$ angles $>50^{\circ},>58^{\circ},>62^{\circ},>70^{\circ}$, and $>83^{\circ}$. A Pearson correlation analysis was performed to assess for correlations among $\alpha$ angles, LCE angles, offset ratios, patient age, and the grade of osteoarthritis. A correlation coefficient $(r)<0.3$ was considered to indicate a weak correlation; $0.3-0.7$, a moderate correlation; and $>0.7$, a high correlation. A $p$ value $<0.05$ was considered statistically significant.

\section{Results}

Shapiro-Wilk analyses showed significant normal distributions for patient age $(p<0.01), \alpha$-angles $(p<0.01)$, and offset ratios $(p=0.01)$. There were 33 hips (13 men, 17 women) without signs of OA (Kellgren-Lawrence grade 0 ). However, 20 hips (11 men, 9 women) showed OA grade 1; 37 hips (14 men, 22 women), OA grade 2; and 24 hips (12 men, 12 women), OA grade 3 . There were 39 patients ( 39 hips; 25 men, 14 women; $34 \%$ of all hips) with a positive cross-over sign. The prevalence of cross-over signs was significantly higher in male patients than in female patients $(p<0.01)$.

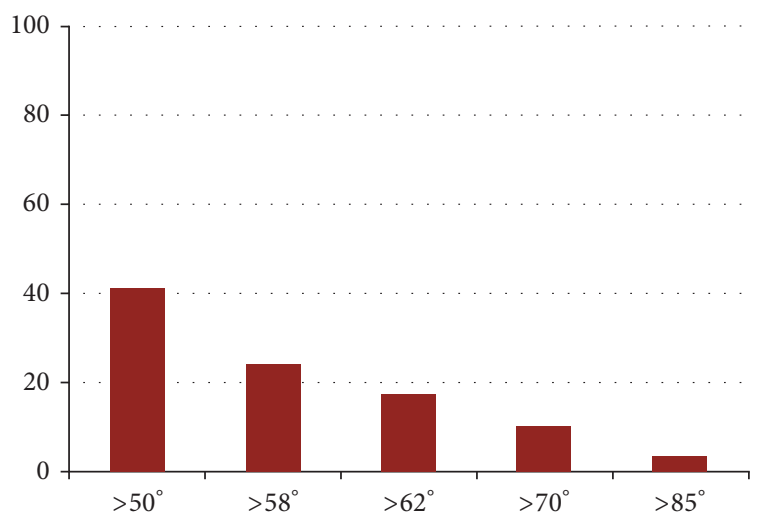

FIGURE 3: The percentage of patients with $\alpha$-angles exceeding different cut-off values.

The mean LCE angle was $30.7^{\circ}$ (range: $13^{\circ}-52^{\circ}$ ), and the mean offset ratio was 0.18 (range: $-0.07-0.33$; Table 1 ). There were 15 patients (13\%; 5 men, 10 women) with LCE angles $\geq$ $40^{\circ}$ and 49 patients (43\%; 30 men, 19 women) with an offset ratio $<0.18$. Female patients showed significantly higher LCE angles compared with males $(p=0.01)$. In contrast, male patients showed significantly lower offset ratios compared with females $(p<0.01$; Table 1$)$.

The mean $\alpha$-angle was $50.9^{\circ}$ (range: $33^{\circ}-89^{\circ}$ ). There were 47 patients ( 30 men, 17 women) with $\alpha$-angles $>50^{\circ}$ (mean: $69.5^{\circ}$; range: $\left.51^{\circ}-89^{\circ}\right)$; 28 patients ( 21 men, 7 women) with $\alpha$-angles $>58^{\circ}$ (mean: $63.3^{\circ}$; range: $59^{\circ}-89^{\circ}$ ); and 4 patients ( 2 men, 2 women) with $\alpha$-angles $>83^{\circ}$ (mean: 63.3 ; range: $84^{\circ}-89^{\circ}$ ). Figure 3 shows the percentage of patients with $\alpha$ angles exceeding different cut-off values. Male patients had significantly higher $\alpha$-angles compared with females $(p<$ 0.01).

Correlation analysis showed a moderate correlation between LCE angles and patient age $(r=0.365, p<0.01)$. No correlation was found between age and offset ratios $(r=$ $0.169, p=0.07)$ or between age and $\alpha$-angles $(r=-0.131$, $p=0.17)$. 
TABLE 1: Mean LCE angles, $\alpha$-angles, and offset ratios for male patients, female patients, and all patients. The right column shows $p$ values for comparisons between men and women.

\begin{tabular}{lcccc}
\hline & $\begin{array}{c}\text { Male patients } \\
(n=53)\end{array}$ & $\begin{array}{c}\text { Female patients } \\
(n=61)\end{array}$ & $\begin{array}{c}\text { Mean } \\
(n=114)\end{array}$ & $\begin{array}{c}\text { Stat. difference } \\
\text { between } \\
\text { male/female patients }\end{array}$ \\
\hline LCE angles (range) & $28.9^{\circ}\left(13^{\circ}-52^{\circ}\right)$ & $32.3^{\circ}\left(21^{\circ}-46^{\circ}\right)$ & $30.7^{\circ}\left(13^{\circ}-52^{\circ}\right)$ & $p=0.01$ \\
Offset ratio & $0.15(-0.07-0.31)$ & $0.20(-0.06-0.33)$ & $0.18(-0.06-0.33)$ & $p<0.01$ \\
$\alpha$-Angles & $54.7^{\circ}\left(35^{\circ}-89^{\circ}\right)$ & $47.6^{\circ}\left(33^{\circ}-88^{\circ}\right)$ & $50.9^{\circ}\left(33^{\circ}-89^{\circ}\right)$ & $p<0.01$ \\
\hline
\end{tabular}

TABLE 2: Overall prevalence of FAI signs.

\begin{tabular}{lc}
\hline Signs of FAI & Prevalence in \% (number of pat.) \\
\hline 1 & $71.9 \%(82 / 114)$ \\
2 & $45.6 \%(52 / 114)$ \\
3 & $15.8 \%(18 / 114)$ \\
4 & 0 \\
\hline
\end{tabular}

TABLE 3: Prevalence of CAM-type FAI signs.

\begin{tabular}{lc}
\hline Signs of FAI & Prevalence in \% (number of pts.) \\
\hline 1 & $43.0 \%(49 / 114)$ \\
2 & $41.2 \%(47 / 114)$ \\
\hline
\end{tabular}

TABLE 4: Prevalence of pincer-type FAI signs.

\begin{tabular}{lc}
\hline Signs of FAI & Prevalence in \% (number of pts.) \\
\hline 1 & $42.1 \%(48 / 114)$ \\
2 & $3.5 \%(4 / 114)$ \\
\hline
\end{tabular}

Similarly, no significant correlation was found between the stage of osteoarthritis and LCE angles $(r=0.176, p=$ $0.06)$, offset ratios $(r=-0.85, p=0.37)$, or $\alpha$-angles $(r=$ $0.105, p=0.26)$.

In summary, 82 patients (71.9\%) showed at least one radiological sign of cam or pincer deformity, 52 patients (45.6\%) showed two, and 18 patients (15.8\%) showed three; none of the patients showed more than three signs (Tables 2, 3, and 4).

\section{Discussion}

These data confirm our hypothesis that a number of asymptomatic people would have signs of cam and pincer deformities on native hip X-rays. This is in accordance with data from studies that have reported FAI signs on hip X-rays of $42.6 \%$ to $53 \%$ of asymptomatic individuals $[23,25,26]$.

The mechanical basis of FAI is the result of a complex, dynamic interaction between the femoral head-neck junction and the acetabular labrum or rim $[27,28]$, which is difficult to assess using two-dimensional imaging techniques. In recent years, assessment of cam deformities has often been performed by measuring $\alpha$-angles at the anterior aspect of the femoral head-neck junction [5, 21, 29-31]. However, several studies have shown that the area of maximum extension of the cam deformity may vary between patients and that the greatest loss of head-neck asphericity is present at either the anterior aspect of the head-neck junction or the anteriorsuperior surface [32-34]. As a result, a straight axial X-ray of the femoral head-neck junction may underproject the maximum extension of the cam deformity in some cases. Likewise, standard anteroposterior X-rays do generally not project the deformity leading to cam FAI [35-37]. Consequently, several native X-ray views have been proposed to measure the $\alpha$ angle, such as the frog-leg lateral view [17], the $45^{\circ}$ and $90^{\circ}$ Dunn views [38], and the cross-table lateral view [18]. Meyer et al. [35] evaluated a number of native X-ray views and found the highest sensitivity in cam deformity detection for the $45^{\circ}$ Dunn view and the cross-table view in $15^{\circ}$ internal rotation. Since the cross-table view showed the highest inter- and intraobserver reliability [35], we decided to use it for our study. A number of studies [23, 25, 26] have evaluated cam deformities in asymptomatic people on the basis of $45^{\circ}$ Dunn views, but studies using internally rotated cross-table views remain sparse.

However, according to the complex, three-dimensional interaction between femoral head-neck junction and acetabular rim, the area with the maximum deformity is not necessarily the area that causes the impingement. Therefore, it is difficult to define a clear threshold when to consider a deformity pathological. Sole measurement of the deformities maximum extension may result in overestimation of the pathology.

In general, the data from this study are consistent with findings from several CT- and MRI-based studies [12, 13, $29,31]$ that have reported the prevalence of cam deformities in asymptomatic patients to be between $10 \%$ and $31 \%$. In contrast to cam FAI, which seems clearly associated with a loss of the femoral head-neck offset [21], the pincer type is more difficult to assess $[1,29,39]$. A prior study has shown a correlation between LCE angles on plain AP X-rays and acetabular overcoverage [40]. Likewise, the cross-over sign has shown a high sensitivity and specificity in detecting acetabular retroversion [29]. In contrast, recent studies have questioned the value of these two measures in the assessment of pincer deformities [24, 41]. Isolated coxa profunda seems to rarely be associated with pincer FAI [39].

In our study, $13 \%$ of patients had an LCE angle $>40^{\circ}$, which is comparable to the $14 \%$ reported by Diesel et al. [39]. In contrast, $34 \%$ of the asymptomatic patients in our study showed positive cross-over signs, which is higher than the $12.6 \%-18.5 \%$ reported from previous research [25, 26, 39]. Signs of pincer impingement were significantly more frequent in females, and cam deformities were significantly more frequent in males. No correlation between age and $\alpha$-angle 
was found. These observations are in line with results from several other studies [25, 30, 34, 39].

What remains unclear is whether asymptomatic people with cam or pincer deformities do not actually impinge, or if they remain asymptomatic because the impingement occurs without causing pain. Furthermore, it is unknown if patients with painless FAI are more likely to develop early OA compared with people without anatomical deformities $[42,43]$.

A recent meta-analysis evaluated the role of prophylactic surgery for asymptomatic FAI [44]. Considering the lack of available evidence and known complication rates as high as $6.4 \%$ after arthroscopic surgery [45], prophylactic surgery could not be recommended for asymptomatic patients with FAI [44].

The major limitations of the current study were the relatively small sample size and its retrospective design.

\section{Conclusion}

According to our data, radiological signs of cam and pincer FAI are frequently found in asymptomatic individuals. In clinical practice, patients presenting with hip pain and native radiological signs of FAI should undergo further diagnostic evaluation. In asymptomatic patients with radiological signs of FAI, however, no further diagnostic studies are recommended.

\section{Conflicts of Interest}

The authors declare that they have no conflicts of interest.

\section{References}

[1] M. Beck, M. Kalhor, M. Leunig, and R. Ganz, "Hip morphology influences the pattern of damage to the acetabular cartilage. Femoroacetabular impingement as a cause of early osteoarthritis of the hip," The Journal of Bone \& Joint Surgery (British Volume), vol. 87, no. 7, pp. 1012-1018, 2005.

[2] R. Ganz, P. Bamert, P. Hausner, B. Isler, and F. Vrevc, "Cervicoacetabular impingement after femoral neck fracture," Unfallchirurg, vol. 94, no. 4, pp. 172-175, 1991.

[3] R. Ganz, J. Parvizi, M. Beck, M. Leunig, H. Nötzli, and K. A. Siebenrock, "Femoroacetabular impingement: a cause for osteoarthritis of the hip," Clinical Orthopaedics and Related Research, vol. 417, pp. 112-120, 2003.

[4] D. A. Goodman, J. E. Feighan, A. D. Smith, B. Latimer, R. L. Buly, and D. R. Cooperman, "Subclinical slipped capital femoral epiphysis. Relationship to osteoarthrosis of the hip," The Journal of Bone \& Joint Surgery, vol. 79, no. 10, pp. 1489-1497, 1997.

[5] M. Leunig, P. E. Beaulé, and R. Ganz, "The concept of Femoroacetabular impingement: Current status and future perspectives," Clinical Orthopaedics and Related Research, vol. 467, no. 3, pp. 616-622, 2009.

[6] M. Leunig, M. M. Casillas, M. Hamlet et al., "Slipped capital femoral epiphysis: early mechanical damage to the acetabular cartilage by a prominent femoral metaphysis," Acta Orthopaedica, vol. 71, no. 4, pp. 370-375, 2000.
[7] S. W. Snow, D. Keret, S. Scarangella, and J. R. Bowen, "Anterior impingement of the femoral head: A late phenomenon of LeggCalvé-Perthes disease," Journal of Pediatric Orthopaedics, vol. 13, no. 3, pp. 286-289, 1993.

[8] N. J. Giori and R. T. Trousdale, "Acetabular retroversion is associated with osteoarthritis of the hip," Clinical Orthopaedics and Related Research, no. 417, pp. 263-269, 2003.

[9] K. A. Siebenrock, R. Schoeniger, and R. Ganz, "Anterior femoroacetabular impingement due to acetabular retroversion. Treatment with periacetabular osteotomy," The Journal of Bone \& Joint Surgery, vol. 85, no. 2, pp. 278-286, 2003.

[10] H. Eijer, D. A. Podeszwa, R. Ganz, and M. Leunig, "Evaluation and treatment of young adults with femoro-acetabular impingement secondary to Perthes' disease," Hip International, vol. 16, no. 4, pp. 273-280, 2006.

[11] D. Reynolds, J. Lucas, and K. Klaue, "Retroversion of the acetabulum," The Journal of Bone \& Joint Surgery (British Volume), vol. 81, no. 2, pp. 281-288, 1999.

[12] K. Hack, G. Di Primio, K. Rakhra, and P. E. Beaulé, "Prevalence of cam-type femoroacetabular impingement morphology in asymptomatic volunteers," The Journal of Bone \& Joint Surgery, vol. 92, no. 14, pp. 2436-2444, 2010.

[13] S. Reichenbach, P. Juni, S. Werlen, E. Nuesch, C. W. Pfirrmann, S. Trelle et al., "Prevalence of cam-type deformity on hip magnetic resonance imaging in young males: a cross-sectional study," Arthritis Care and Research, vol. 62, no. 9, pp. 1319-1327, 2010.

[14] J. J. Nepple, J. M. Vigdorchik, and J. C. Clohisy, "What is the association between sports participation and the development of proximal femoral cam deformity?" The American Journal of Sports Medicine, vol. 43, no. 11, pp. 2833-2840, 2015.

[15] M. J. Philippon, C. P. Ho, K. K. Briggs, J. Stull, and R. F. Laprade, "Prevalence of increased alpha angles as a measure of cam-type femoroacetabular impingement in youth ice hockey players," The American Journal of Sports Medicine, vol. 41, no. 6, pp. 13571362, 2013.

[16] K. A. Siebenrock, I. Kaschka, L. Frauchiger, S. Werlen, and J. M. Schwab, "Prevalence of cam-type deformity and hip pain in elite ice hockey players before and after the end of growth," The American Journal of Sports Medicine, vol. 41, no. 10, pp. 23082313, 2013.

[17] J. C. Clohisy, R. M. Nunley, R. J. Otto, and P. L. Schoenecker, "The frog-leg lateral radiograph accurately visualized hip cam impingement abnormalities," Clinical Orthopaedics and Related Research, no. 462, pp. 115-121, 2007.

[18] H. Eijer, M. Leunig, M. Mahomed, and R. Ganz, Crosstable lateral radiograph for screening of anterior femoral head-neck offset in patients with femoroacetabular impingement. Hip Int. 2001; 11: 37-41.

[19] J. H. Kellgren and J. S. Lawrence, "Radiological assessment of osteo-arthrosis," Annals of the Rheumatic Diseases, vol. 16, no. 4, pp. 494-502, 1957.

[20] G. Wiberg, "Studies on dysplastic acetabula and congenital subluxation of the hip joint: with special reference to the complication of osteoarthritis," Acta Chirurgica Scandinavica, vol. $83,58,1939$.

[21] H. P. Nötzli, T. F. Wyss, C. H. Stoecklin, M. R. Schmid, K. Treiber, and J. Hodler, "The contour of the femoral head-neck junction as a predictor for the risk of anterior impingement," The Journal of Bone \& Joint Surgery, vol. 84, no. 4, pp. 556-560, 2002. 
[22] M. Tannast, K. A. Siebenrock, and S. E. Anderson, "Femoroacetabular impingement: radiographic diagnosis-what the radiologist should know," American Journal of Roentgenology, vol. 188, no. 6, pp. 1540-1552, 2007.

[23] A. C. Johnson, M. A. Shaman, and T. G. Ryan, "Femoroacetabular impingement in former high-level youth soccer players," The American Journal of Sports Medicine, vol. 40, no. 6, pp. 13421346, 2012.

[24] I. Zaltz, B. T. Kelly, I. Hetsroni, and A. Bedi, "The crossover sign overestimates acetabular retroversion hip," Clinical Orthopaedics and Related Research, vol. 471, no. 8, pp. 2463-2470, 2013.

[25] C. V. Diesel, T. A. Ribeiro, R. B. Scheidt, C. A. De Souza Macedo, and C. R. Galia, "The prevalence of femoroacetabular impingement in radiographs of asymptomatic subjects: A crosssectional study," Hip International, vol. 25, no. 3, pp. 258-263, 2015.

[26] R. B. Scheidt, C. R. Galia, C. V. Diesel, R. Rosito, and C. A. D. S. Macedo, "Prevalence of radiographic markers of femoroacetabular impingement in asymptomatic adults," Revista do $C B C$, vol. 41, no. 1, pp. 36-42, 2014.

[27] M. Lamontagne, N. Brisson, M. J. Kennedy, and P. E. Beaulé, "Preoperative and postoperative lower-extremity joint and pelvic kinematics during maximal squatting of patients with cam femoro-acetabular impingement," The Journal of Bone \& Joint Surgery, vol. 93, no. 2, pp. 40-45, 2011.

[28] M. Lamontagne, M. J. Kennedy, and P. E. Beaule, "The effect of cam FAI on hip and pelvic motion during maximum squat," Clinical Orthopaedics and Related Research, vol. 467, no. 3, pp. 645-650, 2009.

[29] A. C. L. Kang, A. J. Gooding, M. H. Coates, T. D. Goh, P. Armour, and J. Rietveld, "Computed tomography assessment of hip joints in asymptomatic individuals in relation to femoroacetabular impingement," The American Journal of Sports Medicine, vol. 38, no. 6, pp. 1160-1165, 2010.

[30] J. Kim, J.-A. Choi, E. Lee, and K. R. Lee, "Prevalence of imaging features on CT thought to be associated with femoroacetabular impingement: A retrospective analysis of 473 asymptomatic adult hip joints," American Journal of Roentgenology, vol. 205, no. 1, pp. W100-W105, 2015.

[31] P. Omoumi, C. Thiery, N. Michoux, J. Malghem, F. E. Lecouvet, and B. C. Vande Berg, "Anatomic features associated with femoroacetabular impingement are equally common in hips of old and young asymptomatic individuals without CT signs of osteoarthritis," American Journal of Roentgenology, vol. 202, no. 5, pp. 1078-1086, 2014.

[32] C. W. A. Pfirrmann, B. Mengiardi, C. Dora, F. Kalberer, M. Zanetti, and J. Hodler, "Cam and pincer femoroacetabular impingement: Characteristic MR arthrographic findings in 50 patients," Radiology, vol. 240, no. 3, pp. 778-785, 2006.

[33] K. S. Rakhra, A. M. Sheikh, D. Allen, and P. E. Beaulé, "Comparison of MRI alpha angle measurement planes in femoroacetabular impingement," Clinical Orthopaedics and Related Research, vol. 467, no. 3, pp. 660-665, 2009.

[34] R. Morales-Avalos, J. I. Leyva-Villegas, G. Sánchez-Mejorada et al., "Prevalence, topographic and morphometric features of femoral cam-type deformity: changes in relation to age and gender," Anatomical Science International, vol. 91, no. 4, pp. 391397, 2016.

[35] D. C. Meyer, M. Beck, T. Ellis, R. Ganz, and M. Leunig, "Comparison of six radiographic projections to assess femoral head/ neck asphericity," Clinical Orthopaedics and Related Research, no. 445, pp. 181-185, 2006.
[36] S. J. Haider, A. H. Siegel, K. F. Spratt, J. B. Ames, J. A. Graham, and Y. Y. Cheung, "Detection of femoroplasty on pre- and post-arthroscopic comparison radiographs following treatment of femoroacetabular impingement syndrome: multireader accuracy and agreement study," Skeletal Radiology, pp. $1-10,2017$.

[37] C. Barton, M. J. Salineros, K. S. Rakhra, and P. E. Beaulé, "Validity of the alpha angle measurement on plain radiographs in the evaluation of cam-type femoroacetabular impingement," Clinical Orthopaedics and Related Research, vol. 469, no. 2, pp. 464-469, 2011.

[38] D. M. Dunn, "Anterversion of the neck of the femur, a method of measurement," The Journal of Bone and Joint Surgery (British Volume), vol. 34, pp. 181-186, 1952.

[39] C. V. Diesel, T. A. Ribeiro, C. Coussirat, R. B. Scheidt, C. A. S. Macedo, and C. R. Galia, "Coxa profunda in the diagnosis of pincertype femoroacetabular impingement and its prevalence in asymptomatic subjects," The Bone \& Joint Journal, vol. 97-B, no. 4, pp. 478-483, 2015.

[40] M. J. Philippon, A. B. Wolff, K. K. Briggs, C. T. Zehms, and D. A. Kuppersmith, "Acetabular rim reduction for the treatment of femoroacetabular impingement correlates with preoperative and postoperative center-edge angle," Arthroscopy - Journal of Arthroscopic and Related Surgery, vol. 26, no. 6, pp. 757-761, 2010.

[41] V. Chadayammuri, T. Garabekyan, M. Jesse et al., "Measurement of lateral acetabular coverage: a comparison between CT and plain radiography," Journal of Hip Preservation Surgery, vol. 2, no. 4, pp. 392-400, 2015.

[42] N. V. Bardakos and R. N. Villar, "Predictors of progression of osteoarthritis in femoroacetabular impingement: A radiological study with a minimum of ten years follow-up," The Journal of Bone \& Joint Surgery (British Volume), vol. 91, no. 2, pp. 162-169, 2009.

[43] G. Hartofilakidis, N. V. Bardakos, G. C. Babis, and G. Georgiades, "An examination of the association between different morphotypes of femoroacetabular impingement in asymptomatic subjects and the development of osteoarthritis of the hip," The Journal of Bone \& Joint Surgery (British Volume), vol. 93, no. 5, pp. 580-586, 2011.

[44] J. A. Collins, J. P. Ward, and T. Youm, "Is prophylactic surgery for femoroacetabular impingement indicated?: A systematic review," The American Journal of Sports Medicine, vol. 42, no. 12, pp. 3009-3015, 2014.

[45] T. G. Sampson, "Complications of hip arthroscopy," Clinics in Sports Medicine, vol. 20, no. 4, pp. 831-835, 2001. 


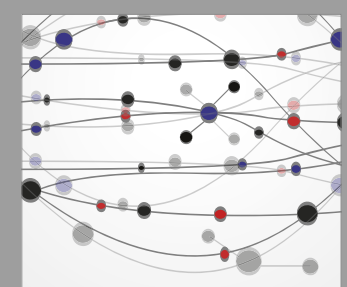

The Scientific World Journal
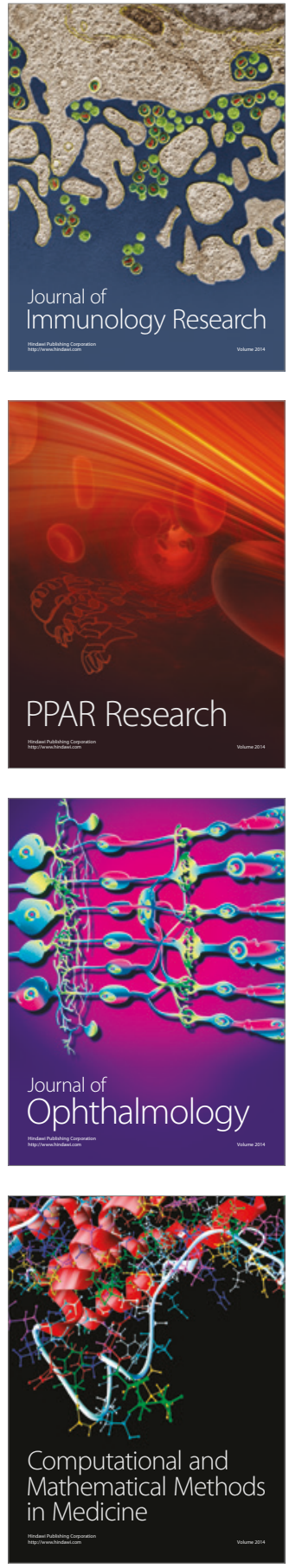

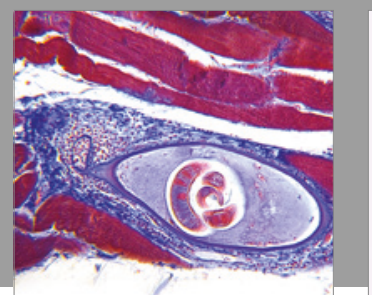

Gastroenterology Research and Practice
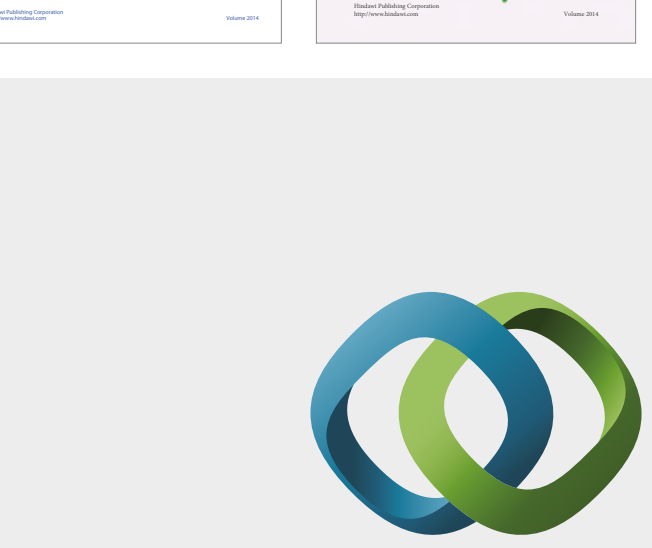

\section{Hindawi}

Submit your manuscripts at

https://www.hindawi.com
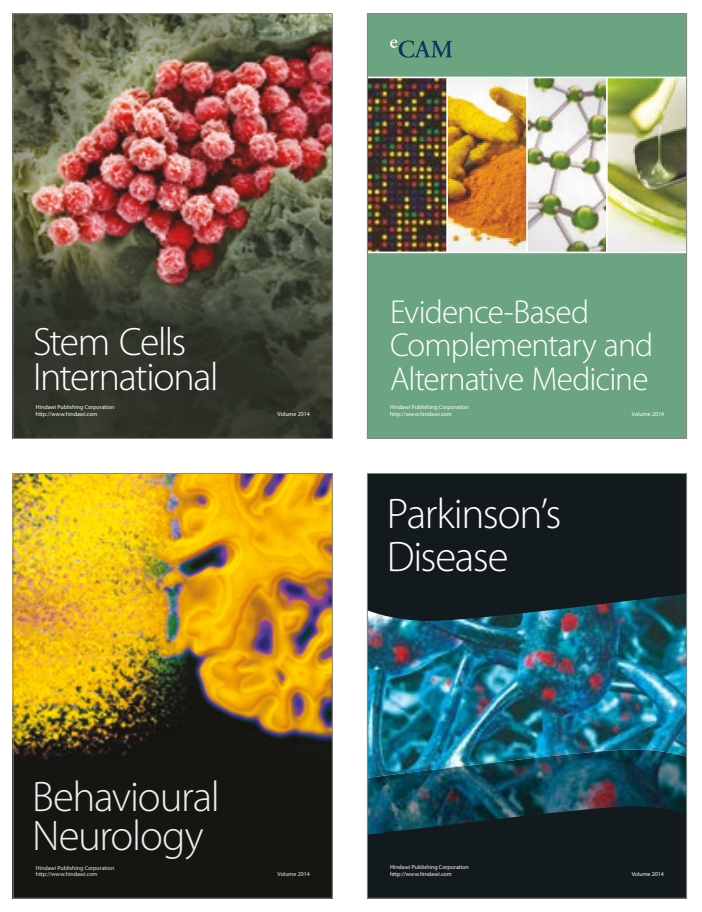
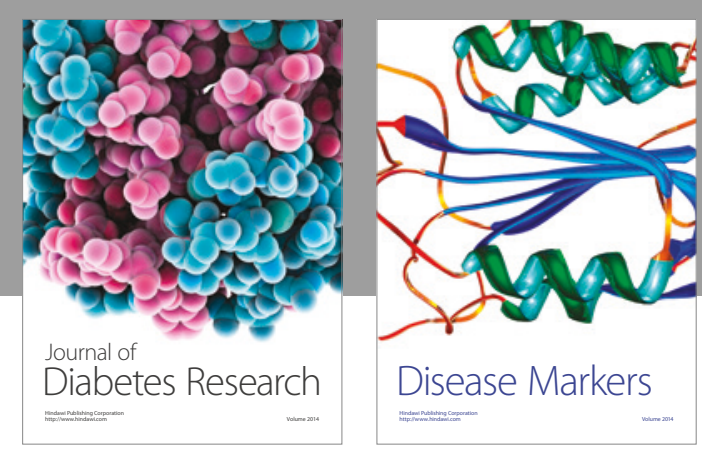

Disease Markers
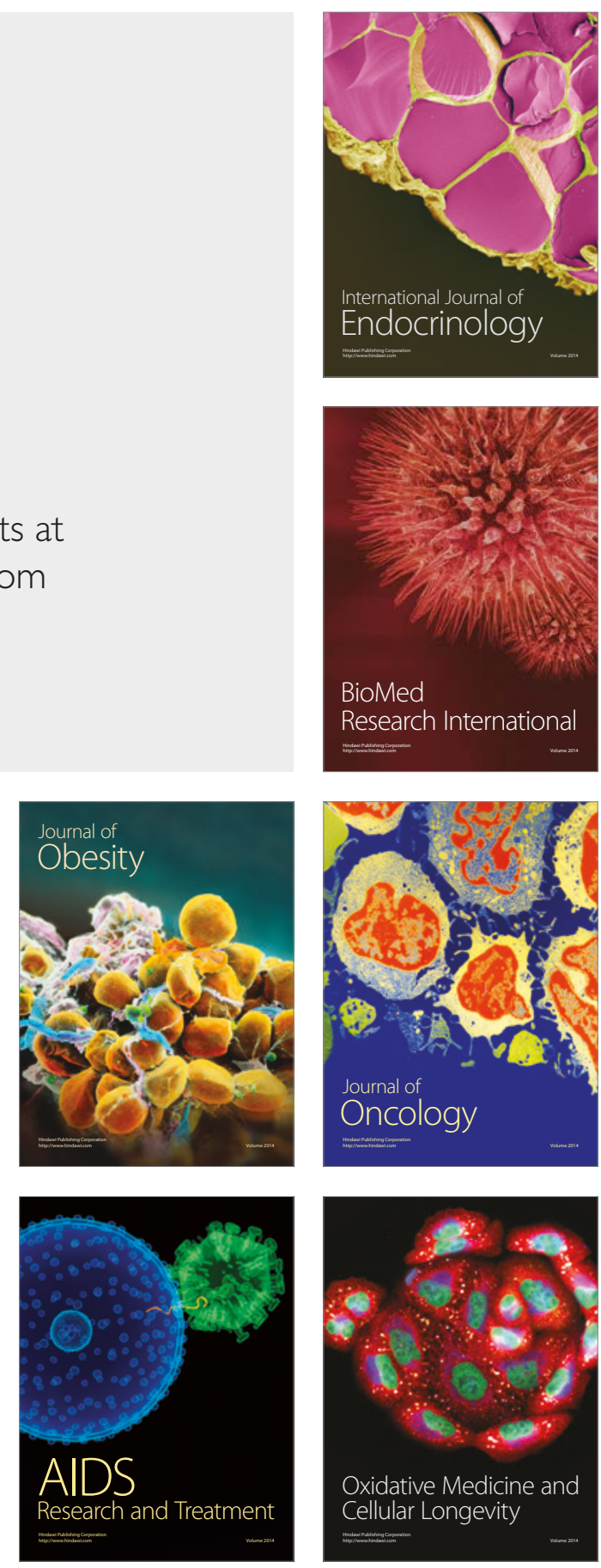